\title{
Programming environments: environmentality and citizen sensing in the smart city
}

\author{
Jennifer Gabrys \\ Department of Sociology, Goldsmiths, University of London \\ e-mail: j.gabrys@gold.ac.uk
}

Published in "A New Apparatus: Technology, Government, and the Resilient City," eds. Bruce Braun and Stephanie Wakefield, Environment and Planning D: Society and Space 32, no. 1 (2014), doi:10.1068/ d16812

\footnotetext{
Abstract

A new wave of smart-city projects is underway that proposes to deploy sensor- based ubiquitous computing across urban infrastructures and mobile devices to achieve greater sustainability. But in what ways do these smart and sustainable cities give rise to distinct material-political arrangements and practices that potentially delimit urban 'citizenship' to a series of actions focused on monitoring and managing data? And what are the implications of computationally organized distributions of environmental governance that are programmed for distinct functionalities and are managed by corporate and state actors that engage with cities as datasets to be manipulated? In this paper I discuss the ways in which smart-city proposals might be understood through processes of
} 
environmentality or the distribution of governance within and through environments and environmental technologies. I do this by working through an early and formative smart-city design proposal, the Connected Sustainable Cities (CSC) project, developed by MIT and Cisco within the Connected Urban Development initiative between 2007 and 2008.

Revisiting and reworking Foucault's notion of environmentality in the context of the CSC smart-city design proposal, I advance an approach to environmentality that deals not with the production of environmental subjects, but rather with the specific spatial-material distribution and relationality of power through environments, technologies, and ways of life. By updating and advancing environmentality through a discussion of computational urbanisms, I consider how practices and operations of citizenship emerge that are a critical part of the imaginings of smart and sustainable cities. This reversioning of environmentality through the smart city recasts who or what counts as a 'citizen' and attends to the ways in which citizenship is articulated environmentally through the distribution and feedback of monitoring and urban data practices, rather than through governable subjects or populations.

Keywords: smart city, sustainable city, environmentality, citizen sensing, biopolitics 2.0, programmed city

\section{Introduction: smart and sustainable cities}

Cities that are infused with and transformed by computational processes seem to be the object of continual reinvention. While informational or 
cybernetically planned cities have been underway since at least the 1960s (Archigram, 1994; Forrester, 1969), proposals for networked or computable cities began to appear as regular features in urban development plans from the 1980s onwards (Batty, 1995; Castells, 1989; Droege, 1997; Gabrys, 2003; Graham and Marvin, 2001; Mitchell, 1995). From designing for the plasticity of urban architecture to envisioning the city as a zone for technologically spurred economic growth, digital city developments have remade urban spaces as networked, distributed, and flexible sites for capital accumulation and urban experience.

More recent and commercially led proposals for 'smart cities' have focused on how networked urbanisms and participatory media might achieve 'greener' or more efficient cities that are simultaneously engines for economic growth. Smart-city proponents commonly make the case for the necessity of these developments by signaling toward trends in increasing urbanization. While cities are centers of economic growth and innovation, they are also, smart-city advocates argue, sites of considerable resource use and greenhouse gas emissions and are therefore seen to be important zones for implementing sustainability initiatives. In these proposals decaying or yet-to-be-built infrastructures are identified as sites of prime smart-city development. Smart cities are presented as a neatly packaged way to meet these generalized challenges, thereby ensuring that future cities_-whether retrofitted or new-are more sustainable and efficient than ever before.

Although cities infused by digital technologies and imaginaries are not 
a new development, their implementation to achieve sustainability directives under the guise of smart cities is a more recent tactic for promoting digital technologies. In many smart-city proposals, computational technologies are meant to synchronize urban processes and infrastructures to improve resource efficiency, distribution of services, and urban participation. Digital technologies, and specifically ubiquitous computing, have become a recurring theme in articulating how sustainable urbanisms might be achieved; yet the intersection of smart and sustainable urbanisms is an area of study that has yet to be examined in detail, particularly in relation to what modalities of urban environmental citizenship are emphasized or even eliminated in the smart city.

This paper takes up the emergence of the smart city as a sustainable city by looking at one particular case study, the Connected Sustainable Cities (CSC) project developed by MIT and Cisco within the Connected Urban Development (CUD) initiative. The CSC aspect of the project consists of design proposals developed between 2007 and 2008 by William Mitchell and Federico Casalegno in the MIT Mobile Experience Lab working in conjunction with Cisco CUD. The Cisco CUD initiative was a partnership initiated in 2006 in response to the Clinton Global Initiative for addressing climate change. Pairing with eight cities worldwide, from San Francisco to Madrid, Seoul, and Hamburg, CUD ran until 2010 and has informed Cisco's ongoing project Smart + Connected Communities, which continues to produce smart- city plans, from development underway in Songdo to proposals to develop a "Sustainable 21st Century San Francisco" (Cisco, no 
date).

Situating this design proposal within a range of smart-city projects that include sustainability in their development plans, I examine how this speculative and early smart- city project proposes to achieve more sustainable and efficient urbanisms through a number of ubiquitous computing scenarios to be adapted to existing and hypothetical cities. The CSC project proposal bears strong resemblances to many smart-city developments still underway and, with its connection to Cisco, one of the primary developers of network architecture for cities, is an influential demonstration of smart-city imaginings. Many of the tools developed through the CUD project consist of planning documents, white papers, eco toolkits, multimedia demonstrations, and speculative designs meant to guide smart-city development. ${ }^{1}$ As an important but perhaps overlooked

\footnotetext{
${ }^{1}$ A paper could be written just on the role of white papers within smart-city developments. Crafted by industry, universities, and governmental agencies, smart-city white papers appear to be a key way in which the imaginings and implementation of these urban developments circulate. The 'circulation' of policy as discussed by Robinson (2011) is part of the way in which cities accumulate multilocated 'elsewheres' within projects of urban imagining. The documents drafted in support of the CUD project are similarly informed by multiple white papers, including Climate Change: Cities in Action (Zhen et al, 2009), which was developed by Cisco, Metropolis, and CUD, and gathers together details of eco-actions by and for cities around the world. At the time of this paper going to press, the CUD project website and papers are being reorganized. Zhen's white paper is no longer available on the CUD website but can be found on the City of Montreal's website, for instance: http:/ / ville.montreal.qc.ca/pls/portal/ docs/PAGE/
} 
part of the process of promoting smart cities, these designs, narratives, and documents have played an important role in rearticulating the smart city as a sustainable city. Importantly, however, this paper focuses on these proposals not simply as discursive renderings of cities, but as elements within an urban computational dispositif or apparatus (Foucault, 1980), which performs material-political relations across speculative designs, technological imaginaries, urban development plans, democratic engagements through participatory media, and networked infrastructures, many of which are folded into present-day urban development plans and practices, even when the smart city is an ever-elusive project to be realized.

Smart-city plans and designs, as proposed and uncertainly realized, articulate distinct materialities and spatialities as well as formations of power and governance. By considering Foucault's concept of environmentality in this context, I examine the ways in which the CSC project performs distributions of governance within and through proposals for smart environments and technologies. I emphasize this aspect of Foucault's (2008) discussion of environmentality in order to open up and develop further his unfinished questioning of how environmental technologies as spatial modes of governance might alter material-political distributions of power and possible modes of subjectification. Revisiting and reworking Foucault's notion of environmentality not as the production of environmental subjects but as a spatial-material distribution and

IIGGM_V2_EN/MEDIA/DOCUMENTS/CLIMATE CHANGE-CITIES IN ACTION (PUBLISHED IN 2009).PDF. 
relationality of power through environments, technologies, and ways of life, I consider how practices and operations of citizenship emerge that are a critical part of the imaginings of smart and sustainable cities. This reading of environmentality in the smart city recasts who or what counts as a 'citizen' and attends to the ways in which citizenship is articulated environmentally through the distribution and feedback of monitoring and urban data practices, rather than as an individual subject to be governed.

The primary way in which sustainability is to be achieved within smart cities is through more efficient processes and responsive urban citizens participating in computational sensing and monitoring practices. Urban citizens become sensing nodes—or citizen sensors—within smart-city proposals. This is a way of understanding 'citizen sensing' not as a practice synonymous with 'citizen science' but as a modality of citizenship that emerges through interaction with computational sensing technologies used for environmental monitoring and feedback. In this context, I take up the proposals for smart cities as developed in the CSC project to ask: what are the implications of computationally organized distributions of environmental governance that are programmed for distinct functionalities and are managed by corporate and state actors that engage with cities as datasets to be manipulated? Which articulations of environmentality emerge within sustainable smart-city proposals and developments when governance is performed through environments that are computationally programmed? And when sensing citizens become operatives within urban computational systems, how might environmental technologies delimit 
citizen-like practices to a series of actions focused on monitoring and managing data? Might this mean that citizenship is less about a fixed human subject, and more about an operationalization of citizenship that largely relies on digital technics to become animate?

\section{Remaking smart cities}

As may be gathered from the multiple literatures and projects directed toward smart cities, there are numerous interpretations for what even counts as a smart city (Allwinkle and Cruickshank, 2011; European Commission, 2011). It could involve new media districts or automated infrastructures equipped with networked digital sensors; it could refer to the correspondence between online and offline worlds, or it might encompass augmented urban experiences made possible through mobile devices. While earlier research on computational urbanisms may have focused on the relationship between the digital and physical city or the ways in which 'virtual' digital technologies might respatialize or represent physical cities (Lovink, 2002; Sassen, 2002), increasingly these approaches have transformed into the ways in which cities are now being remade and marketed through both software and the material infrastructures of digital technologies (Ellison et al, 2007; Galloway, 2004; Graham, 2004). Ubiquitous computing remakes cities rather than displacing or virtually representing them by generating considerable amounts of data to manage urban processes, as well as by directly embedding devices in urban infrastructures and spaces. 
'Smartness', while a generalized reference to computational urbanisms, increasingly refers to urban sustainability strategies that hinge on the implementation of ubiquitous urban computing, or the "fourth utility", as Cisco has termed it (Elfrink, 2009). In an industry white paper, "A theory of smart cities", IBM authors involved with the Smarter Planet initiative suggest that the term "smart cities" derives from "smart growth", a concept used in urban planning in the late 1990s to describe strategies for curtailing sprawl and inefficient resource use, which later changed to describe ITenabled infrastructures and processes oriented toward such objectives (Harrison and Donnelly, 2011). A recurring theme within government and industry white papers on smart cities addresses the ways in which networked sensor technologies are meant to optimize urban processes and resources, including transport, buildings, electricity, and industry, and make them more efficient. Sensor-operationalized and automated environments perform a distinct version of sustainability, where efficiency is the overall goal that informs the merging of economic growth with green objectives. Indeed, smart cities are frequently identified as a hoped-for source of considerable new revenue generation, and in a report funded by the Rockefeller Foundation, the Institute for the Future suggests that smart cities are likely to be a "multi-trillion dollar global market" (Townsend et al, 2010, page 4).

The current wave of smart and sustainable cities projects proposed and underway includes numerous proposals located throughout the world that bear similar objectives, plans, and designs related to economic growth 
through smart and sustainable computational urbanisms. From Abu Dhabi to Helsinki, and from Smart Grids in India to PlanIT Valley in Portugal, many urban development projects are guided by the implementation of networked sensor environments that are marketed through the logics of efficiency and sustainability. Smart-city projects are often set up as publicprivate partnerships between multinational technology companies including Cisco, IBM, and Hewlett Packard, along with city governments, universities, and design and engineering firms. Proposals may involve retrofitting urban infrastructures in New York or London; developing new cities on greenfields in Songdo, Korea or Lake Nona, Florida; or intensifying network utilities in midsized cities like Dubuque, Iowa as test sites for networked sensor applications. The focus here is on the ways in which smartness influences articulations of urban sustainability. But rather than fix a definition of the smart city, I work between suggestions that the ways in which informationalized cities are mobilized can be indicative of political and economic interests (Hollands, 2008), and that digitally informed cities may be figures that continually change in their imagining, implementation, and experiencing (Mackenzie, 2010). Although smart cities could be seen as rather generic and universalizing in their approach to urbanism, many smart cities also emerge through the materially and politically contingent spaces and practices of urban design, policy, and development, while also forming commitments to specific - if speculativeurban ways of life. 


\section{Remaking citizens in smart cities}

The computational technologies proposed and developed in smart-city projects are meant to inform urban environments and processes, along with the interactions and practices of urban citizens. Citizen sensing and participatory platforms are often promoted in smart- city plans and proposals as enabling urban dwellers to monitor environmental events in real-time through mobile and sensing technologies. Yet proposals focused on enabling citizens to monitor their activities convert these citizens into unwitting gatherers and providers of data that may be used not just to balance energy use, for instance, but also to provide energy companies and governments with details about everyday living patterns. Monitoring and managing data in order to feed back information into urban systems are practices that become constitutive of citizenship. Citizenship transforms into citizen sensing, embodied through practices undertaken in response to (and communication with) computational environments and technologies.

Citizen sensing as a form of engagement is a consistent, if differently emphasized, reference point both for development-led and for creativepractice engagements with smart cities. DIY projects propose citizen involvement through the use of participatory media and sensing technologies, and these citizen-sensing projects stress the difference between grassroots and more large-scale smart-city developments. Yet an interesting confluence of imaginaries and practices occurs at the point of tooling up citizens, even to the point of "alter[ing] the subjectivity of contemporary citizenship" by enabling urban dwellers to use sensing 
technologies to interact with urban environments (Borden and Greenfield, 2011). What subjectivity is this, and might computational environments be one place to turn to consider how (and where) this subjectivity and citizenship is altered? In other words, when urban processes and architectures shift through ubiquitous computing deployed for efficiency and sustainability, how do urban material politics and possibilities for democratic engagement also transform (Fuller and Haque, 2008; Greenfield and Shepard, 2007)? My interest in these modalities of citizen sensing within smart cities is not to denounce these proposals and projects as tools of control, which might form a typical technological critique, but rather to understand more precisely the ways in which computational materializations distribute power through urban spaces and processes. As Foucault has suggested, rather than attempt to imagine a space free of power it may be more productive to consider how power is distributed as a way to critique modes of governance by imagining how it might be possible not to be governed quite so much—or in that way (Foucault, 1997, pages 44-45).

\section{Environmentality}

I take up these questions about transformations in urban process, form, and inhabitation in order to analyze in greater detail the ways in which the environmental technologies of ubiquitous computing inform urban governance and citizenship. 'Environmentality' is a term I use to describe 
these urban transformations, which I revisit and rework through a reading of Foucault's unfinished discussion of this concept in one of his last lectures in The Birth of Biopolitics. Foucault signals his interest in environmentality and environmental technologies as he moves from a historical to a more contemporary and neoliberal consideration of biopolitics in relation to the milieu or environment as the site of governance. Here, he suggests the subject or population may be less relevant for understanding the exercise of biopolitical techniques, since alterations of environmental conditions may become a new way to implement regulation (2007, pages 22-23; 2008, pages 259-261). Foucault's discussion of environmentality emerges from an analysis of criminality, where in one example he considers how approaches to regulating the supply of drugs may have had a greater impact on conditions of addiction in comparison with strategies that have targeted individual addicted users or populations of addicted users. Working less with an explanation and more with an open-ended suggestion of what he sees as a growing trend toward environmental governance rather than subject-based or population-based distributions of governance, he notes, "Action is brought to bear on the rules of the game rather than on the players, and finally in which there is an environmental type of intervention instead of the internal subjugation of individuals" (page 260). Moving beyond this example, Foucault gestures toward a broader notion of environmentality where influencing the "rules of the game" through the modulation and regulation of environments may be a more current description of governmentality, above and beyond direct attempts to 
influence or govern individual behavior or the norms of populations.

Behavior may be addressed or governed, but the technique is environmental.

Foucault closes his lecture by indicating that in the following week he would examine in greater detail these questions of environmental regulation. However, he does not develop this strand of thought further, and, instead, his six pages outlining his approach to environmentality are included as a footnote in The Birth of Biopolitics lectures $(2004 ; 2008)$. Consisting more of an unanswered question than a theoretical roadmap, Foucault's discussion of environmentality ranges from a historical analysis of the governing of populations to a consideration of more contemporary modes of governance that may have been unfolding or already underway at the time of his lecture. While his specific concept of environmentality remains a footnote to his discussion of neoliberal modes of governance, it is a provocation for thinking through the effects of the increasing promotion and distribution of computational technologies in order to manage urban environments. In what ways do smart-city proposals for urban development articulate and enact distinctly environmental modes of governance, and what are the spatial, material, and citizenly contours of these modes of governance?

The use of the term 'environmentality' that I am developing and transforming based on the biopolitics lectures is rather different from the ways in which it has often been taken up based on Foucault's earlier work, from the making of environmentally aware subjects for the purposes of 
forest conservation in India (Agrawal, 2005) to the use of environmentality as a term to capture the "green governmentality" of environmental organizations (Luke, 1999). Environmentality as a concept does offer up ways of thinking about governance toward environmentalist objectives. But it is important to bear in mind the translations that are made across environmentality and environmentalism. Foucault's analysis of environmentality does not directly pertain to environmentalism as such, but rather to an understanding of governance through the milieu. ${ }^{2}(2)$ In fact, Foucault's interest in environmental modes of governance touches on strategies of "environmental technology and environmental psychology" (2008, page 259), fields that could include designing survival systems or shopping mall experiences (eg, Anker, 2005; Banham, 1984). Environmental modes of governance are also as likely to emerge from the failure to meet environmentalist objectives. Events such as Hurricane Katrina, as Massumi suggests in his analysis of environmentality, generate distinct modes of crisis-oriented governance that emerge in relation to the uncertainty of climate change- a condition of "war and weather" that sets in motion a spatial politics of ongoing disruption and response (2009, page 154).

\footnotetext{
${ }^{2}$ While the English version of this passage in The Birth of Biopolitics translates this term as "environmentalism", in the French original Foucault uses the term "environnementalité", which is much closer to conveying the sensing of governmentality distributed through environments, rather than a social movement oriented toward environmental issues (see Foucault, 2004, page 266; 2008, page 261).
} 


\section{Biopolitics 2.0}

Foucault's discussion of environmentality, however abbreviated, addresses the role of environmental technologies in governance and in many ways relates to his abiding attention to the milieu as a site of biopolitical management. Biopolitics, or the governing of life, as he analyzed it in its late 18th and 19th-century formations, was concerned with "control over relations between the human race, or human beings insofar as they are a species, insofar as they are living beings, and their environment, the milieu in which they live" (2003, pages 244-245). If we further take biopolitics to include those distributions of power that inform not just life, but also how to live (Foucault, 2003, pages 239-245), then how are ways of life governed through these particular environmental distributions? Indeed, the phrase "ways of life", which Foucault deploys to discuss biopolitical arrangements and distributions of power, is taken up by Revel to suggest that biopolitics is a concept that is not exclusively concerned with 'control', as perhaps has been overemphasized through readings of Foucault's earlier work, but that focuses on the spatial-material conditions and distributions of power that are characteristic of and relatively binding within any given time and place (2009, pages 49-52). 'Ways of life', or 'life lived', is a biopolitical concept and approach that also moves beyond understandings of life as a given biological entity [this reading of biopolitics may have more to do with Agamben's work on biopolitics and bare life (see 1998)] and, instead, suggests that ways of life are situated, emergent, and practiced through 
spatial and material power relations. Such a concept does not describe a totalizing schema of power but points to understandings of how power emerges and operates within ways of life, as well as suggesting possibilities for generating alternative ways of life.

A different formation of biopolitics emerges in the context of environmentality, since biopolitics unfolds in relation to a milieu that is less oriented toward control over populations and instead performs through environmental modes of governance. In order to capture and examine the ways of life that emerge within the CSC smart-city proposal, I use the term biopolitics 2.0 (with a hint of irony) to refer to the participatory or ' 2.0 ' digital technologies at play within smart cities, and to examine specific ways of life that unfold within the smart city. Biopolitics 2.0 is a device for analyzing biopolitics as a historically situated concept, a point that Foucault stressed in his development of the term. The 2.0 of biopolitics captures the situatedness of this term, which includes the proliferation of user-generated content through participatory digital media that is a key part of the imagining of how smart cities are to operate; it also includes the versioning of digital technologies through the transition of computation from desktops to environments (Hayles, 2009), whether in the shape of mobile digital devices or sensors embedded in urban infrastructure, objects, and networks- something that is captured by the term 'City 2.0 ', which circulates as a parallel term to the smart city.

The biopolitical milieu generates material-spatial arrangements in which and through which distinct dispositifs, or apparatuses, operate. The 
apparatus of computational urbanism can be analyzed through networks, techniques, and relations of power that extend from infrastructure to governance and planning, everyday practices, urban imaginaries, architectures, resources, and more. But this "heterogeneous ensemble" can be described through the "nature of the connection" that unfolds across these elements (Foucault, 1980, page 194). In his discussions on biopolitics, the apparatus, and the milieu Foucault repeatedly suggests that the ways in which relations are performed are key to understanding how modes of governance, ways of life, and political possibilities emerge or are sustained.

Computational monitoring and responsiveness characterize the "nature of the connection" across environments and citizens in smart cities. Biopolitical 2.0 relations are performed through the need to promote economic development while addressing impending environmental calamity, conditions characterized by an urgency that Foucault critically identifies as being crucial to the historical situation of the apparatus and, consequently, to the operation of biopolitics (1980, pages 194-195; see also Agamben, 2009). Within smart-city proposals and projects, cities are presented as urgent environmental, social, and economic problems that the digital reorganization of urban infrastructures is meant to address by increasing productivity while achieving efficiency. By drawing together Foucault's understanding of how power might operate environmentally and biopolitically, I shift the emphasis toward understanding urban spaces and citizenship within relational or connective registers, with an emphasis on the computational practices and processes that are meant to remake and 
influence smart-city ways of life. In reading and contextualizing these aspects of Foucault as less focused on disciplined or controlled subjects or populations, I also bring environmentality into a space where it is possible to consider how smart cities qualify environmentality by recasting what counts as "the rules of the game".

To say that smart cities might be understood through a biopolitics 2.0 analysis is not so much to suggest that digital technologies are simply tools of control as to examine how the spatial and material programs that are imagined and implemented within smart-city proposals generate distinct types of power arrangements and modes of environmentality and entangle urban dwellers within specific performances of citizenship. But within these programs for computational urbanism, the processual and practiced ways of life that unfold or are proposed to unfold inevitably materialize in multiple ways. The "rules of the game" that Foucault described as central to environmentality might need to be revised as a less static or deterministic rendering of how governance works. Smart-city design proposals on one level establish propositions and programs for how computational urbanisms are to operate; but on another level, programs never go according to plan and are never singularly enacted. Environmentality might be advanced by considering smart cities not as the running of code in a command-and-control logic of governing space but as the multiple, iterative, and even faltering materializations of imagined and lived computational urbanisms. 


\section{Connected sustainable cities}

Working at this juncture of environmental modes of governance, environmental technologies, and sustainability as they are operationalized in smart cities, the CSC project within the CUD puts forward a vision for a near future of ubiquitous urban computing oriented toward increased sustainability. The project proposal materials advocate the smart city as the key to addressing issues of climate change and resource shortages, where sustainable urban environments may be achieved through intelligent digital architectures. The CSC design proposals and policy tools, as well as the core visioning document-Connected Sustainable Cities (2008), authored by Mitchell and Casalegno_-develop scenarios for everyday life enhanced, and even altered, by smart information technologies, which "will support new, intelligently sustainable urban living patterns".

Within the CSC design proposals the technology that most operationalizes smart environments and the programmed interactions between city and citizens is ubiquitous computing in the form of "continuous, fine-grained electronic sensing" through "sensors and tags" that are "mounted on buildings and infrastructures, carried in moving vehicles, integrated with wireless mobile devices such as telephones, and attached to products". Sensor devices are distributed throughout and monitor the urban environment. The continual generation of data provides "detailed, real-time pictures" of urban practices and infrastructures that can be managed, synched, and apportioned to support "the optimal allocation of scarce resources" (Mitchell and Casalegno, 2008, page 97). Digital sensor 
technologies perform urban processes as a project of efficiency, where environments are embedded with computational technologies that provide urban management and regulation.

Like many smart-city proposals, the CSC sites are made smart through several common areas of intervention largely oriented toward increasing productivity while enhancing efficiency. A video lays out the rationale for the project and the core areas it addresses, including platforms developed to aid commuting, home recycling, self-managing one's carbon footprint, facilitating flexibility in urban spaces, and collaborative decision making as model areas in which improved efficiency by means of digital connectivity and improved visibility of environmental data may save resources and lower greenhouse gas emissions. While many of the applications envisaged in the proposal are already in use within cities, from electronic bicycle rental schemes to smart meters for managing energy use, the project suggests a further coordinated dissemination of sensor technologies and platforms for achieving more efficient urban processes.

In the CUD project video and CSC design document, urban design and planning proposals take place not necessarily at the scale of the master plan, but rather at the scale of the scenario. From Curitiba to Hamburg, the episodic urban patterns addressed in these designs and policies include urban services, eco-monitoring toolkits, and speculative platforms intended to achieve smart and 'seamless' automated living. Yet in many cases the urban interventions take place in a hypothetical city or in a specified city that is rendered sufficiently general as to be receptive to computational 
interventions within a universalized language of the everyday. In a design scenario sketched out for 'managing homes' in Madrid, numerous capabilities are proposed to make homes more efficient. Mobile phones are GPS-enabled to communicate with sensor-equipped kitchen appliances, so that a family dinner may be cooked by balancing location and timing. The home thermostat will similarly sync with GPS and calendars on mobile phones, so that the home is heated in time for the family's arrival. The organization of activities unfolds through programmed and activated environments so as to realize the most productive and efficient use of time and resources. In the Madrid scenario, monitoring residents' behaviors in detail through sensors and data is essential for achieving efficiency. With this information, environments are meant to become self-adjusting and to perform optimally.

The CSC efficiency initiatives promise to "streamlin[e] the management of cities", lessen environmental footprints, and "enhanc[e] how people experience urban life" (Mitchell and Casalegno, 2008, page 2). By tracking locations and daily activities, smart technologies present the possibility that dinners will self-cook and homes will self-heat. These "enabling technologies" perform new arrangements of environments and ways of life: "smart" thermostats couple with calendars, locations, and even "a human body's 'bio-signals", and "skin temperature and heart rate" may be monitored through sensors to ensure optimum indoor temperatures. Similarly, communication with kitchen appliances is proposed to occur through "Toshiba's 'Femininity' line of home network appliances". These 
technologies ensure the home will be warm, safe, and provided with the latest recipes (pages 58-59).

The importance of the everyday as a site of intervention signals the ways in which smart-city proposals are generative of distinct ways of life, where a "microphysics of power" is performed through everyday scenarios (Deleuze, 1995, page 97). Governance and the managing of the urban milieu occur not through delineations of territory, but through enabling the connections and processes of everyday urban inhabitations within computational modalities. The actions of citizens have less to do with individuals exercising rights and responsibilities, and more to do with operationalizing the cybernetic functions of the smart city. Participation involves computational responsiveness and is coextensive with actions of monitoring and managing one's relations to environments, rather than advancing democratic engagement through dialogue and debate. The citizen is a data point, both a generator of data and a responsive node in a system of feedback. The program of efficiency assumes that human participants will respond within the acceptable range of actions, so that smart cities will function optimally. Yet programs for efficiency that are multiply distributed will inevitably be multiply enacted across human and more-than-human registers, so that smart bicycles are left in creeks and sensing devices are hacked to surreptitiously monitor domestic environments or intervene in them. This smart-city proposal raises questions as to how these orchestrated ways of life would be actually lived, thereby rerouting programs of efficiency and productivity. 


\section{Programming environments}

As specifically rendered through smart technologies, the motivating logic of sustainability becomes oriented toward saving time and resources. This in turn informs proposals for how to embed smart technologies within everyday environments in order to ensure more efficient ways of life. Monitoring is a practice enabled by sensors and so it becomes a central activity in articulating the sustainability and efficiency of smart cities. The sensing that takes place in the smart city involves continually monitoring processes in order to manage them. The urban sense data generated through smart-city processes are meant to facilitate the regulation of urban processes within a human-machine continuum of sensing and acting, such that "the responsiveness of connected sustainable cities can be achieved through well-informed and coordinated human action, automated actuation of machines and systems, or some combination of the two" (Mitchell and Casalegno, 2008, page 98). Humans may participate in the sensor city through mobile devices and platforms, but the coordination across "manual and automated" urban processes unfolds within programmed environments, which organize the inputs and outputs of humans and machines.

'The programmed city' is a speculative and actual project that has been critical to the ongoing development of ubiquitous computing, but which has also demonstrated the complicated and uncertain ways in which 
programmable environments are realized (Gabrys, 2010, page 58 and passim). ${ }^{3}$ Programming as described in the CSC document has multiple resonances, signaling the architectural sense of programming space for particular activities (cf Mitchell, 2003) as well as the programming of urban development and policy, and the computational programming of environments. Within smart-city proposals, programming of environments is a way in which the "nature of the connection" within the computational dispositif is performed across a spatial arrangement of digital devices, software, cities, development plans, citizens, practices, and more.

The notion of programming, while specific to computation, is further coupled with notions of what the environment is and how it may be made programmable. Some of the early imaginings of sensor environments speculate on how everyday life may be transformed with the migration of computation from the desktop to the environment (Weiser, 1991). While many of these visions are user focused, environmental sensors also transform notions of how or where sensing takes place to encompass more distributed and nonhuman modalities of sensing (Gabrys, 2007; 2012; Hayles, 2009). The programming of environments is perhaps one of the key ways in which 'the milieu' is now best described as 'the environment', since the postwar rise of the term 'the environment' corresponds with more cybernetic approaches to systems and ecology (Haraway, 1991) and with

\footnotetext{
${ }^{3}$ This paper is part of a forthcoming book, Program Earth: Environment as Experiment in Sensing Technology, which is focused on environmental sensing and programmed environments. This paper also relates to an ongoing
} 
the use of the term 'environment' to describe the computing environment, referring to the conditions in which computation can operate.

A growing body of research in the area of software studies now focuses on the intersection of computation and space, making the point that computing —often in the form of software or code—-has a considerable influence on the ways in which spatial processes unfold or even cease to function when software fails (Graham, 2005; Kitchin and Dodge, 2011; Thrift and French, 2002). While software is increasingly informing spatial and material processes, I situate the performativity of software within (rather than above or prior to) the material-political- technical operations of the computational dispositif, since programmability necessarily signals more than the unfurling of scripts that act on the world in a discursive architecture of command-and-control. Software is also not so easily separated from the hardware it would activate (Gabrys, 2011; Kittler, 1995). Instead, as I suggest here, programmability points to the ways in which computational logics are performed across material-cultural situations, even at the level of speculative designs or imaginings of political processes (where computational approaches to perceived urban 'problems' may inform how these issues are initially framed in order to be computable), while indicating how actual programs may not run according to plan.

The computational articulations of governance and citizenship within the CSC proposals are uncertain indicators for how urban practices might

research project related to digital sensor technologies and environmental practice, "Citizen Sense" (see http:/ / www.citizensense.net). 
actually unfold, even when processes are meant to be automated for efficiency-but it is exactly the faltering and imperfect aspects of programmed environments that might become sites for political encounters in smart cities. Some smart-city initiatives are finding that the less 'modern' political structures of city councils, for instance, do not make for easily compatible smart-city development contexts. Urban governance may be divided into multiple wards or councils across and through which the seamless flow of data and implementation of digital infrastructures may be complicated or halted. "Realizing programs of action" within software development "is complicated and contested", as Mackenzie notes (2005, page 88 ). Code is also not singularly written or deployed but may be a hodgepodge of just-effective-enough script written by multiple actors and running in momentarily viable ways on specific platforms. A change to any element of the code, hardware, or interoperability with other devices may shift the program and its effects. When code is meant to reprogram urban environments, it also becomes entangled in complex urban processes that interrupt the simple enactment of scripts.

The CSC proposals also demonstrate the ways in which the programmed environments of the smart city give rise to-and even require-distinct urban materialities in order to be operable. The several modalities of sensing and programming that emerge within the CSC documentation are expressive of programs to sense and monitor in order to manage and regulate the material processes of the smart-city environment, from the circulation of people and goods to processes of participation, all of 
which are seen to interconnect through the "digital nervous system" of the smart city (Mitchell and Casalegno, 2008, pages 5-6). In the CSC scenarios the metabolic circuit of inputs and outputs that is made optimally efficient simplifies the processes necessary to transform urban materialitiesthrough electronicizing, tagging, and monitoring - in order to make them programmable and efficient. Ubiquitous urban computing would require a considerable outlay of materials and resources in order for cities to operate in these modalities. Urban materialities are then doubly elided through the dematerializing logic of digital technology, since automation, improved timing, and coordination seem to minimize-and even eliminate-the resource requirements and wastes of smart cities; electronic technologies also seem to have no resource requirements, whether in their manufacture, operation, or disposal. Resource requirements and material entanglements are apparently minimized through the improved flow offered by smart technologies. Yet digital technologies—and the digital apparatus—are generative of processes of materialization that do not so much elide materialities as transform them through computational modalities (Gabrys, 2011). The uneven and material ways in which computation unfolds within cities breaks with this kind of frictionless understanding of how computation might seamlessly perform a set of efficiency objectives. Smart cities could be characterized as much by the gaps and accidents of computational technologies, which are also part of the "experience" of how these devices and systems perform and are implemented (Mackenzie, 2010). 


\section{Programming participation}

The infrastructures at play in the CSC vision partially consist of grids and services remade into smart electrical grids, smart transport, and smart water. But they also consist of participatory and mobile citizen-sensing platforms through which urban dwellers are to monitor environments and engage with smart systems. Participatory media and environmental devices facilitate this more sustainable city by enabling forms of participation that are compatible with it. The smart infrastructures and citizen-sensing platforms in the CSC project enable monitoring practices, while structuring responses that regulate or recalibrate everyday practices. Sustainable transit options become more viable through the deployment of "urban citizenship engagement points" (Connected Urban Development, no date a) that allow for personalized planning of bus routes, carpooling, and bicycle rental. Energy contributions may be made at the intersection of smart transit systems or architectural surfaces and mobile monitoring devices. Urban spaces may be easily reconfigured or adapted to allow working and networking in any location at any time, and to facilitate the "intensification of urban land use". The way in which these practices are activated occurs across the programs embedded within urban environments and mobile devices. Digitally enhanced infrastructure and citizens are articulated as corresponding nodes, where technologies and strategies for environmental efficiency become coextensive with citizen participation-and "changed human behavior" (ibid).

While additional design scenarios address traffic in Seoul and work- 
anywhere-anytime proposals for Hamburg, as well as coordinating public transit in San Francisco and using mobile platforms to organize daily health monitoring, one scenario based in an unnamed North American urban location focuses on "taking personal responsibility" through the narrative of a love contest between two male friends vying for the attentions of an eco-female (Mitchell and Casalegno, 2008, page 102). This scenario demonstrates how "the biggest variable in sustainability" — that is, "human behavior" - may be monitored and advanced effectively through ICT applications. The male competitors in this scenario engage in logging their daily travel plans online to generate carbon footprints for comparison; installing a home monitoring system to measure electricity use; and monitoring water use to generate a water budget. As the scenario outlines:

"Monitor, monitor, monitor ... that's a lot of what both men do. They realize that the key to winning Joan's heart is to show her they're making the right decisions, and that means they need a lot of clear information that is meaningful—and actionable" (Mitchell and Casalegno, 2008, pages 89-91).

Monitoring behavior and generating data is the basis for making sound decisions to advance everyday sustainable practices. Programs of responsiveness are critical to the ways in which sustainable practices are designed to emerge in this smart-city proposal. In order for these schemes to function, urban citizens need to play their part, whether by partaking in transport systems or by generating energy through their continual movement within urban environments. Urban environmental citizens are 
responsible for making "informed, responsible choices" (Mitchell and Casalegno, 2008, page 2). Yet these proposals explicitly outline the repertoire of actions and reflections that the smart city will enable, in which the sensing citizen becomes an expression of productive infrastructures. Mitchell and Casalegno stress the benefits of informed participation in urban processes facilitated by participatory media and ubiquitous computing-technologies that, they argue, make a heightened sense of responsibility possible (page 101). Urban citizenship is remade through these environmental technologies, which mobilize urban citizens as operatives within the processing of urban environmental data; citizen activities become extensions and expressions of informationalized and efficient material-political practices. Citizens who sense and track their own consumption patterns and local environmental processes have a set of citizen-like actions at their disposal, enabled by environmental technologies that allow them to be participants within the smart city.

The balancing of smart systems with citizen engagement is typically seen as a necessary area to address when considering the issues of surveillance and control that smart cities may generate. As the previously cited Rockefeller-funded report suggests, global technology companies such as IBM and Cisco may have a rather different set of objectives than "citizen hacktivists", and yet both these companies have vested interests in contributing to emerging smart-city proposals (Townsend et al, 2010). Digital technologies are seemingly liberating tools, allowing citizens to engage in ever more democratic actions; and yet, the monitoring and 
capture of sensor-data within nearly every aspect of urban life vis-à-vis devices deployed by global technology companies suggest new levels of control. But could it be that this apparent dichotomy between sensing citizen and smart city is less clear-cut? In many ways participatory media could already be seen as tools of variously restricted political engagement (Barney, 2008), while smart urban infrastructures never quite manifest (if at all) in the totalizing visions presented.

The sensing citizen could be seen to be an expression of the ideal mode of citizen participation in smart-city visions, rather than a resisting agent to them. Sensing citizens are the necessary participants in smart cities-where smart cities are the foregone conclusion. Dumb citizens in smart cities would be a totalitarian overshoot, since they would be entities subject to monitoring without participating in the flow of information. The smart city raises additional questions about the politics of urban exclusion, about who is able to be a participating citizen in a city that is powered through access to digital devices. Yet the participatory agency that is embedded within smart-city developments does not settle on an individual human subject, and citizenship is instead articulated through environmental operations. Within the CSC proposals there exists the possibility that given a possible failure or limitation of human responsiveness-a lack of interest in participating in the smart city - the system may operate on its own. In these scenarios, due to a lack of "human attention and cognitive capacity" as well as a desire not to "burden people with having to think constantly about controlling the systems that surround them", it may be relevant to 
deploy "automated actuation", the project authors suggest. This would mean that urban systems become self- managing such that "buildings and cities will evolve towards the condition of rooted-in-place robots" (Mitchell and Casalegno, 2008, page 98). Citizens might be seen as figures responding within the program of environmentality. However, the smartcity program is able to operate independently by sensing environments as well as actuating them and intervening in them to the point where environmental technologies may override citizens if they do not perform according to preset functions-or the rules of the game.

Processes of regulating urban environments within smart-city proposals do not require internal subjugation as such, since governance is distributed within environments that default to automatic modes of regulation. Here is a version of biopolitics 2.0, where monitoring behavior is less about governing individuals or populations and more about establishing environmental conditions in which responsive (and correct) modes of behavior can emerge. Environmentality does not require the creation of normative subjects, as Foucault suggests, since the environmental citizen is not governed as a distinct figure; rather, environmentality is an extension of the actions and forces-automaticity and responsiveness—embedded and performed within environments. Such a situation could be characterized as what Deleuze calls the making of "dividuals", a term he uses to describe the fluid entity that emerges within a "computer" age (1995, page 182). For Deleuze, automation is coextensive with a deindividualizing set of processes characterized by patterns of 
responsiveness that rely less on individual engagement and more on the correct cybernetic connection.

Working transversally with this concept, however, I would suggest that smart-city proposals signal less toward the elimination of individuals absolutely, since the 'citizen' is an important operator within these spaces. Rather, the citizen works through processes that might generate ambividuals: ambient and malleable urban operators that are expressions of computer environments. While the ambividual is not an expression of a cognitive subject, it does articulate the distribution of nodes of action within the smart city. Ambividuals are not singularly demarcated or erased, but variously contingent and responsive to fluctuating events, which are managed through informational practices. This resonates with Foucault's suggestion that one characteristic of environmental technologies is the development of "a framework around the individual which is loose enough for him to be able to play" (2008, page 261). But I would suggest that who or what counts as an ambividual is not restricted to a human actor in the smart city, since the articulation of actions and responses occurs across human-to-machine and machine-to-machine fields of action.

\section{Citizen sensing and sensing citizens}

A final point of consideration that emerges within smart city and citizensensing frameworks is the extent to which environmental monitoring leads to actionable data. Smart-city infrastructures are projected to operate as a self-regulating environment, but the monitoring technologies that are 
meant to enable efficiencies within these systems are less obviously able to generate efficiencies or action within 'citizen' practices. In a CSC scenario demonstrating the types of urban environmental citizenship made possible within the green and digital city, proposals are made for residents of Curitiba to experience enhanced and synchronized mass-transit options while monitoring and reporting on air pollution at these nodes. Citizen reporting and community engagement are amplified by virtue of ICT connectivity. Through these monitoring and reporting capabilities, positive changes are seen to follow as a result of increased information and connectivity: gather the air pollution data, report to the relevant political body, and environmental justice will be realized. These activities and concerns are presented as universally applicable, in that anyone may have cause to monitor and collect pollution data and diligently forward this on to relevant governmental parties. The ambividual actions 'coded' into these processes do not presuppose a particular subject, since a fully automated sensor may equally perform such a function. Rather, these programs of responsiveness allow for a fully interchangeable procession of human-tomachine or machine-to-machine data operations.

A similar trajectory is typically envisaged for self-regulating citizen activities: information on energy consumption will be made visible, a correcting action will be taken, and balance to the cybernetic-informational system will be restored. In these scenarios environmental technologies monitor environments and citizens, while citizens monitor environments and themselves. Citizens armed with environmental data are seen to be 
central democratic operators within these environments. But the 'governing' contained within cybernetics may not neatly translate into the governing of environments (cf Wiener, 1965). It may be that the very responsiveness that enables citizens to gather data does not extend to enabling them to meaningfully act upon the data gathered, since this would require changing the urban 'system' in which they have become effective operators. Similarly, dominant, if problematic, narratives within sustainability of continued growth through improved efficiency and ongoing monitoring typically do not mobilize an overall resource or waste reduction (what is well known within energy discourse as the 'rebound effect'). Strategies of monitoring and efficiency might be seen to co-opt urbanites into modes of environmentality and biopolitics that leave modes of neoliberal power unexamined, since the aim of realizing sustainability objectives through citizen engagement is seen to be a worthy pursuit.

Foucault's broader interest within the biopolitics lectures was in how neoliberal analyses are brought to bear on governance and subjects, such that economic logics of efficiency inform what may have previously been understood through social or noneconomic modalities (2008, pages 246247). Environmentality describes the distribution of governance within environments as well as a qualification of governmentality through a market logic that would implement efficiency and productivity as the best guiding principles for urban ways of life. Individuals become governable to the extent that they operate as homo economicus (page 252), where governance unfolds as an environmental distribution of possible responses 
made according to the criteria of efficiency and maximum utility.

The transformation of citizens to data-gathering nodes potentially focuses the complexity of civic action toward a relatively reductive if legible set of actions. Participation in this smart and sustainable city is instrumentalized both in terms of remedying environment issues through efficiency, and through devices that will harvest and connect up information to arrive at this outcome. Yet the informational and efficiencybased approach to monitoring environments raises more questions about what constitutes effective environmental action than it answers. In order for such instrumentalization to occur, urban processes and participation directed toward sustainability in many ways must be programmed to be amenable to a version of (computational) politics that is able to operate on these issues. The modes of sensing as monitoring and responsiveness presented within many sensor-focused and smart-focused cities projects raise the question of whether a 'citizen' might be more than an entity that emerges within parameters of acceptable responsiveness.

\section{Conclusion: from networks to relays, from programs to ways of life}

The smart sustainable city vision discussed here is presented as a technical solution to political and environmental issues—an approach that could be seen to be characteristic of many smart-city projects. While the CSC and CUD project proposals are developed as conceptual- level design and planning documents, many of the questions raised here about how smart cities and citizen monitoring projects organize political participation and 
the imagining of urban environmental citizenship are relevant for considering the proliferation of projects now taking place in these areas, both at the level of community engagement and through urban policy and development partnerships (eg, European Commission, 2011).

As I have argued, sustainable smart-city proposals give rise to new modes of environmentality as well as biopolitical configurations of governance through distinctly digital dispositifs. Given Foucault's focus on the historical specificity of these concepts and the events to which they refer, it is timely to revisit and revise these concepts in the context of newly emerging smart-city proposals. The environmentality, biopolitics 2.0 , and digital political technologies that unfold through many smart-city proposals are expressive of distributions of governance and operations of citizenship within programmed environments and technologies. A biopolitics 2.0 emerges within smart cities that involves the programming of environments and citizens for responsiveness and efficiency. Such programming is generative of political techniques for governing everyday ways of life, where urban processes, citizen engagements, and governance unfold through the spatial and temporal networks of sensors, algorithms, databases, and mobile platforms that constitute the environments of smart cities.

The environmentality that emerges through proposals for urban sustainability within the CSC project and many similar smart-city projects involves monitoring, economizing, and producing a vision of digitalized economic growth. Such smart cities present ways of life that are 
orchestrated toward sustainability objectives characterized by productivity and efficiency. The data that develop through these practices are generative of practices of monitoring environments and activities, while activating environmental modes of governance that are located not exclusively within the jurisdiction of 'public' authorities but may also extend to technology companies that own, manage and use urban data. From Google Transit to Cisco TelePresence, HP Halo, and Toshiba Femininity, a range of environmental sensor and participatory technologies function in the CSC and other smart-city scenarios that are tools of neoliberal governance, and are operated across state and nonstate actors.

I have emphasized how Foucault's interest in environmentality can be advanced in the context of smart cities to consider how distributions of power within and through environments and environmental technologies are performative of the operations of citizenship-rather than of the individual subjectness of citizenship. The 'environmentalist' aspects of the smart and sustainable city are not contingent on the production of an environmentalist or reflexively ecological subjectivity, and the performance of smart urban citizenship occurs not by expanding the possibilities of democratically engaged citizens, but rather by delimiting the practices constitutive of citizenship. The 'rules of the game' of the smart city do not articulate reversals, openings, or critiques of urban environmental ways of life. Rather, practices are made efficient, streamlined, and oriented toward enhancing existing economic processes. And yet, within this approach to environmentality through smart cities, what we might take as the rules or 
program of the smart-city game might be understood less as a deterministic coding of cities and more as something that might unevenly materialize in practices and events. While design proposals put forward a persuasively singular case for the smart-city program, inevitably multiple smart cities emerge through the circulation and implementation of this program.

But pushing Foucault's notion of environmentality even further, I suggest that his concept of the "rules of the game" might be recast in the context of smart cities less as rules and more as programs- here of responsiveness - that delimit and enable in particular ways, but that also unfold, materialize, or fail in unexpected ways. If urban programs are not singular and are continually in process, then environmentality might also be updated to address the ways in which programs do not go according to plan, and work-arounds might also emerge. Such an approach is not so much a simple recuperation of human resistance as a suggestion that programs are not fixed, and that in their unfolding and operating they inevitably give rise to new practices of urban environmental citizenship and ways of life that emerge across human and more-than-human urban entanglements.

This approach to ways of life is important in formulating not a simple denunciation of the smart city, but rather a proposal for how to attend to the distinct environmental inhabitations and modalities of citizenship —and possibilities for urban collectives - that emerge in smart- city proposals and developments. Subjectification, which Deleuze (1995) discusses as an important concept in Foucault's work, is ultimately concerned not with the 
production of fixed subjects, but rather with the possibility of identifying, critiquing, and even creating ways of life (pages 83-118). Smart-city projects require an attention to-and critique of-the ways of life that are generated and sustained in these proposals and developments. Critique, as articulated in a conversation between Deleuze and Foucault, can be an important way in which to experiment with political engagements and form "relays" between "theoretical action and practical action" (Foucault, 1977, page 207). From this perspective the ways of life proposed in the CSC scenarios might serve as provocation for thinking through how to experiment with urban imaginaries and practices in order not to be governed like that. If we read biopolitics 2.0 as a concept attentive to the ways of life that are generated and sustained within smart cities, and if this computational apparatus operates environmentally, then what new relays for theory and practice might emerge within our increasingly computational urbanisms?

\section{Acknowledgements}

A version of this text was first presented at "The Green Apparatus" session of the American Association of Geographers in Seattle (2011). Thanks to Bruce Braun and Stephanie Wakefield for organizing this session and subsequent theme issue. Thanks are also due to Natalie Oswin for her editorial guidance in shaping this paper. Versions of this paper have also been presented at "Platform Politics", Anglia Ruskin University (2011), the Digital Media Research Seminar, University of Western Sydney (2012), the “Media Places: Infrastructure, Space, Media" symposium, HUMlab at 
Umeå University (2012), and the "Speculative Urbanisms" seminar, Urban Salon, University College London (2013). Thanks are also due to the European Research Council Starting Grant scheme for the project "Citizen Sensing and Environmental Practice", which has enabled work undertaken toward the completion of this paper.

\section{References}

Agamben G, 1998 Homo Sacer: Sovereign Power and Bare Life translated by D Heller-Roazen (Stanford University Press, Stanford, CA)

Agamben G, 2009, What is an Apparatus? translated by D Kishik, S Pedatella (Stanford University Press, Stanford, CA)

Agrawal A, 2005 Environmentality: Technologies of Government and the Making of Subjects (Duke University Press, Durham, NC)

Allwinkle S, Cruickshank P, 2011, “Creating smart-er cities: an overview" Journal of Urban Technology 18 1-16

Anker P, 2005, "The closed world of ecological architecture" The Journal of Architecture 10 527-552

Archigram, 1994 A Guide to Archigram, 1961-74 (Academy Editions, London)

Banham R, 1984 Architecture of the Well-tempered Environment: Theory and Design in the First Machine Age (University of Chicago Press, Chicago, IL) Barney D, 2008, "Politics and emerging media: the revenge of publicity" 
Global Media Journal 1 89-106

Batty M, 1995, “The computable city” International Planning Studies 2 155173

Borden E, Greenfield A, 2011, "You are the smart city", http: / / blog.xively.com/2011/06/30/ you-are-the-smart-city /

Castells M, 1989 The Informational City: Information Technology, Economic Restructuring, and the Urban-Regional Process (Blackwell, Oxford)

Cisco, no date, “Smart + connected communities", http: / www.cisco.com/ web/strategy/smart_connected_communities.html

Connected Sustainable Cities, no date, http: / / connectedsustainablecities.com/

Connected Urban Development, no date a, http: / / www.connectedurbandevelopment.org/, https: / / web.archive.org/web / 20130621085500/ http: / / www.connectedur bandevelopment.org/

Connected Urban Development, no date b, “Connected urban development visions from MIT's Mobile Experience Lab" video, http: / / www.connectedurbandevelopment.org/, https: / / web.archive.org/web / 20130621085500/ http: / / www.connectedur bandevelopment.org, http: / / vimeo.com / 6145800

Deleuze G, 1995 Negotiations: 1972-1990 translated by M Joughin (Columbia University Press, New York) 
Droege P (Ed.), 1997 Intelligent Environments: Spatial Aspects of the Information Revolution (Elsevier, Amsterdam)

Elfrink W , 2009, “Intelligent urbanization” video, http: / / blogs.cisco.com/news/ video/

Ellison N, Burrows R, Parker S (Eds) 2007, “Urban informatics: software, cities and the new cartographies of knowing capitalism" Information, Communication and Society 10 785-960

European Commission, 2011, "Report of the meeting of advisory group. ICT infrastructure for energy-efficient buildings and neighborhoods for carbon-neutral Cities", http: / / ec.europa.eu/information_society / activities / sustainable_growth/d ocs / smart-cities / smart-cities-adv-group_report.pdf Forrester J W, 1969 Urban Dynamics (MIT Press, Cambridge, MA) Foucault M, 1977, “Intellectuals and power: a conversation between Michel Foucault and Gilles Deleuze", in Language, Counter-memory, Practice translated by D Bouchard, S Simon (Cornell University Press, Ithaca, NY) pp 205-217

Foucault M, 1980, “The confession of the flesh", in Power/Knowledge: Selected Interviews and Other Writings 1972-1977 translated by C Gordon, L Marshall, J Mepham, K Soper (Vintage Books, New York) pp 194-228 Foucault M, 1997 The Politics of Truth translated by L Hochroth, C Porter (Semiotext(e), Los Angeles, CA) 
Foucault M, 2003 Society Must Be Defended translated by D Macey (Penguin, London)

Foucault M, 2004 La Naissance de la Biopolitique Cours au Collège de France 1978-1979 (Éditions du Seuil/ Gallimard, Paris)

Foucault M, 2007 Security, Territory, Population: Lectures at the Collège de France 1977-1978 translated by G Burchell (Palgrave Macmillan, New York) Foucault M, 2008 The Birth of Biopolitics: Lectures at the Collège de France 1978-1979 translated by G Burchell (Palgrave Macmillan, New York) Fuller M, Haque U, 2008, “Urban versioning system” Situated Technologies Pamphlets 2 (The Architectural League of New York)

Gabrys J, 2003, “Cité Multimédia: noise and contamination in the information city", conference proceedings from "Visual Knowledges", University of Edinburgh, Edinburgh, 17-20 September, http: / / webdb.ucs.ed.ac.uk/ malts / other/VKC/ dsp-abstract.cfm?ID=84, http: / / www.jennifergabrys.net/wpcontent/uploads / 2003/09/Gabrys_InfoCity_VKnowledges.pdf Gabrys J, 2007, “Automatic sensation: environmental sensors in the digital city" The Senses and Society 2 189-200

Gabrys J, 2010, "Telepathically urban", in Circulation and the City: Essays on Urban Culture Eds A Boutros, W Straw (McGill-Queens University Press, Montréal) pp 48-63

Gabrys J, 2011 Digital Rubbish: A Natural History of Electronics (University of 
Michigan Press, Ann Arbor, MI)

Gabrys J, 2012, “Sensing an experimental forest: processing environments and distributing relations" Computational Culture 2,

http: / / computationalculture.net/ article/ sensing-an-experimental-forestprocessing-environments-and-distributing-relations

Galloway A, 2004, “Intimations of everyday life: ubiquitous computing and the city" Cultural Studies 18 384-408

Graham S (Ed.), 2004 The Cybercities Reader (Routledge, London)

Graham S, 2005, “Software-sorted geographies" Progress in Human

Geography 29 562-80 Graham S, Marvin S, 2001 Splintering Urbanism:

Networked Infrastructures, Technological Mobilities and the Urban Condition

(Routledge, London)

Greenfield A, Shepard M, 2007, “Urban computing and its discontents"

Situated Technologies Pamphlets 1 (The Architectural League of New York)

Haraway D, 1991 Simians, Cyborgs and Women: The Reinvention of Nature

(Routledge, New York)

Harrison C, Donnelly I A, 2011, "A theory of smart cities", Proceedings of the 55th Annual Meeting of the International Society for the Systems Sciences (ISSS),

http: / /journals.isss.org/index.php/proceedings55th/article/view / 1703 Hayles N K, 2009, “RFID: human agency and meaning in informationintensive environments" Theory, Culture and Society 26 47-72

Hollands R G, 2008, “Will the real smart city please stand up?” City 12 303320 
Kitchin R, Dodge M, 2011 Code/Space: Software and Everyday Life (MIT Press, Cambridge, MA)

Kittler F A, 1995, “There is no software” CTHEORY

http: / / www.ctheory.net/ articles.aspx?id=74

Lovink G, 2002, “The digital city: metaphor and community”, in Dark Fiber: Tracking Critical Internet Culture (MIT Press, Cambridge, MA) pp 42-67 Luke T W, 1999, “Environmentality as green governmentality”, in Discourses of the Environment Ed. É Darier (Blackwell, Oxford) pp 121-151 Mackenzie A, 2005, “The performativity of code: software and cultures of circulation" Theory, Culture and Society 22 71-92

Mackenzie A, 2010 Wirelessness: Radical Empiricism in Network Cultures (MIT Press, Cambridge, MA)

Massumi B, 2009, "National enterprise emergency" Theory, Culture and Society 26 153-185

Mitchell W J, 1995 City of Bits: Space, Place, and the Infobahn (MIT Press, Cambridge, MA)

Mitchell W J, 2003 Me++: The Cyborg Self and the Networked City (MIT Press, Cambridge, MA)

Mitchell W J, Casalegno F, 2008 Connected Sustainable Cities (MIT Mobile Experience Lab Publishing, Cambridge, MA), http: / / connectedsustainablecities.com/downloads / connected_sustainable _cities.pdf

Revel J, 2009, "Identity, nature, life: three biopolitical deconstructions" Theory, Culture and Society 26 45-54 
Robinson J, 2011, “The spaces of circulating knowledge: city strategies and global urban governmentality", in Mobile Urbanism Cities and Policymaking in the Global Age Eds E McCann, K Ward (University of Minnesota Press, Minneapolis, MN)

Sassen S (Ed.), 2002 Global Networks, Linked Cities (Routledge, London) Thrift N, French S, 2002, "The automatic production of space" Transactions of the Institute of British Geographers, New Series 27 309-335

Townsend A, Maguire R, Liebhold M, Crawford M, 2010, “A planet of civic laboratories: the future of cities, information, and inclusion", Institute for the Future and the Rockefeller Foundation, Palo Alto, CA Weiser M, 1991, “The computer for the 21st century” Scientific American 265 94-104

Wiener, N, 1965 Cybernetics: Or the Control and Communication in the Animal and the Machine (MIT Press, Cambridge, MA)

Zhen Z et al 2009, “Climate change: cities in action” (Metropolis and Cisco),

http: / / www.connectedurbandevelopment.org/publications / external\#citi es-in-action-for-climate- change, http: / / ville.montreal.qc.ca/pls / portal/docs/PAGE/IIGGM_V2_EN/ME DIA/DOCUMENTS / CLIMATE CHANGE- CITIES IN ACTION (PUBLISHED IN 2009).PDF 